\title{
How executive functions are associated with event-based and time- based prospective memory during childhood
}

\author{
Sascha Zuber ${ }^{\mathrm{a}, \mathrm{b}, \mathrm{c}, *}$, Caitlin E.V. Mahy ${ }^{\mathrm{d}}$, Matthias Kliegel ${ }^{\mathrm{a}, \mathrm{b}, \mathrm{c}}$ \\ ${ }^{a}$ Center for the Interdisciplinary Study of Gerontology and Vulnerability, University of Geneva, Geneva, Switzerland \\ ${ }^{\mathrm{b}}$ Swiss National Center of Competences in Research LIVES - Overcoming vulnerability: life course perspectives, Geneva, Switzerland \\ ${ }^{\mathrm{c}}$ Department of Psychology, University of Geneva, Geneva, Switzerland \\ ${ }^{\mathrm{d}}$ Department of Psychology, Brock University, St Catharines, Ontario, Canada
}

\section{A R T I C L E I N F O}

\section{keywords:}

Prospective memory

Development

Children

School-age

Executive functions

Time-based

Focal

Nonfocal

\begin{abstract}
A B S T R A C T
A key developmental task of childhood is to gain autonomy and independence from parents and caregivers. Critical to this individualization process is the development of prospective memory (PM), the capacity to remember to carry out future intentions. In recent studies, children's PM performance has been associated with executive functions (EF). A closer inspection of the literature, however, suggests a differential impact of the three EF (updating, inhibition, and shifting) across different PM task types. The current study examined EF and PM capacities of 212 6- to 11year-old children, examining for the first time both focal and nonfocal event-based PM tasks as well as a time-based PM task in a single sample. Results show that age-differences did not persist above and beyond age differences in children's executive resources. Specifically, updating predicted children's performance on all PM tasks, inhibition predicted performance on both eventbased PM tasks, whereas shifting was specifically deployed by the nonfocal event-based task. Supplementary analyses of the time-based PM task illustrate how children monitor the progression of time and how preparatory processes support PM task performance. In sum, the current study presents the first comprehensive look at the specific role of age and three core $\mathrm{EF}$ in school-aged children's PM performance.
\end{abstract}

\section{Introduction}

Over the course of childhood, a key developmental task is to gain independence from parents and caregivers in order to become increasingly autonomous. This process is closely related to the development of prospective memory (PM), that is, the ability to remember to perform previously planned actions after a certain delay and without external guidance (e.g., Brandimonte, Einstein, \& McDaniel, 1996; Ellis \& Kvavilashvili, 2000). Everyday examples for children would be remembering to go to music class on Tuesday at 6 p.m. or remembering to wish a friend a happy birthday when encountering her in the schoolyard. PM tasks are highly prevalent in everyday life (Kliegel \& Martin, 2003), and have important implications for several domains of children's development, including academic achievement, personal safety, as well as social relations (e.g., Chen, Lian, Yang, Liu, \& Meng, 2017; McCauley \& Levin, 2004). One key feature of PM tasks is that they are embedded in an ongoing activity, such that one has to remember to perform the prospective task (e.g., remembering to congratulate a friend), while performing another task (labeled ongoing task; e.g., playing a

\footnotetext{
* Corresponding author at: Department of Psychology, Cognitive Aging Lab, University of Geneva, Boulevard du Pont d'Arve 40, 1211 Genève 4, Switzerland.

E-mail address: Sascha.Zuber@unige.ch (S. Zuber).
} 
game with another friend). Conceptually, these everyday life examples mentioned above illustrate two different types of PM tasks: certain PM tasks have to be performed at a specific point in time (e.g., going to music class at 6 p.m.) and are therefore labeled timebased PM tasks (e.g., Einstein, Richardson, Guynn, Cunfer, \& McDaniel, 1995), whereas others have to be performed when/after a specific event occurs (e.g., wishing a friend a happy birthday when running into her in the schoolyard) and are therefore called event-based PM tasks. Event-based PM tasks can be further distinguished into two subtypes, that is, focal versus nonfocal event-based tasks (McDaniel \& Einstein, 2000). This distinction refers to the degree of procedural overlap between performing the ongoing task and detecting the PM cue, which signals that the PM task has to be performed. For example, if participants' ongoing task was to name objects depicted on a series of cards, a focal event-based PM task (for readability purposes henceforth referred to as focal PM tasks) would be to refrain from naming the object and putting the card in a designated box instead whenever the card depicts a chair. This represents a focal task, as there is a high overlap between performing the ongoing task and detecting the PM cue: both tasks require participants to decipher the name of the objects represented on the cards. A nonfocal event-based PM task (for readability purposes henceforth referred to as nonfocal PM tasks), on the other hand, would be if one had to refrain from naming the object but put the card in a designated box whenever a small dot (presented on each trial above or below the central object) would be of a particular color. In this example, the overlap between the ongoing and the PM task is lower, because in addition to deciphering the name of the objects, in order to successfully detect the PM cue one also has to check whether the surrounding dots are of a particular color.

From a developmental perspective, the literature has established that first successful PM performance can be observed at preschool-age (e.g., Guajardo \& Best, 2000; Mahy, Moses, \& Kliegel, 2014b; Somerville, Wellman, \& Cultice, 1983; Wang, Kliegel, Liu, \& Yang, 2008; Zhang, Zuber, Liu, Kliegel, \& Wang, 2017). In general, performance on all three types of PM tasks subsequently improves over childhood (e.g., Aberle \& Kliegel, 2010; Kliegel \& Jäger, 2007; Kvavilashvili, Messer, \& Ebdon, 2001; Zimmermann \& Meier, 2006; but also see Nigro, Senese, Natullo, \& Sergi, 2002, for no age-related increases in PM) and reaches a peak toward the end of adolescence or the beginning of young adulthood (Altgassen, Kretschmer, \& Schnitzspahn, 2017; Maylor \& Logie, 2010; Wang et al., 2011; Wang, Kliegel, Yang, \& Liu, 2006; Zöllig et al., 2007). Comparing the different PM types, the literature suggests that children succeed at performing focal tasks earlier in life compared to nonfocal or time-based tasks (Aberle \& Kliegel, 2010; Rendell, Vella, Kliegel, \& Terrett, 2009). Similarly, age-effects are typically smaller on focal, compared to nonfocal or time-based PM tasks (e.g., Kliegel et al., 2013; Nigro et al., 2002). Such developmental differences have been associated with cognitive resources that are required to perform the PM task: the detection of the PM cue can rely more strongly on automatic/bottom-up processes in focal tasks (see the multiprocess framework by McDaniel and Einstein (2000)), whereas in nonfocal and time-based tasks cue detection more strongly requires attentional resources, as one has to strategically monitor for the appearance of the PM cue or PM target-time.

Despite the general consensus on conceptual and developmental differences between the three PM task-types, the cognitive mechanisms that underlie and predict performance on different PM tasks still seems relatively unexplored, particularly in children. Several studies have suggested executive functions (EF) as one group of cognitive processes that importantly contribute to children's PM (see Mahy, Moses, \& Kliegel, 2014a, for a review). EF can be defined as the processes involved in the conscious control of one's thoughts and actions (Zelazo, Carlson, \& Kesek, 2008). They are deployed by complex tasks, such as making plans, solving problems, organizing and structuring time, maintaining attention, or adapting to novel, unpredictable situations (e.g., Atkinson \& Shiffrin, 1968; Diamond, 2013; Norman \& Shallice, 1986). Although there are different theoretical models that have conceptualized EF, studies on PM and EF have mostly adopted the three function model (Miyake et al., 2000). According to this model, EF are composed of three distinguishable but related cognitive functions, namely updating (i.e. processes enabling the manipulation of information stored in working memory) inhibition (i.e., processes enabling one to refrain from performing prepotent responses and to resist distraction), and shifting (i.e., processes enabling the reallocation of one's attention between different task sets; Miyake et al., 2000).

In recent years, there has been increasing evidence supporting the idea that EF capacities are linked to successful prospective remembering. First, correlational studies show that individual differences in EF and PM are strongly associated, meaning that high performance on one domain is typically associated to high performance on the other domain, and vice versa (Ford, Driscoll, Shum, \& Macaulay, 2012; Kerns, 2000; Mackinlay, Kliegel, \& Mantyla, 2009; Mahy \& Moses, 2011). Second, developmental studies document a similar trajectory of EF and PM: both domains show marked increases in performance during the early childhood years in particular (e.g., Carlson \& Moses, 2001; Guajardo \& Best, 2000; Kliegel \& Jäger, 2007; Mahy \& Moses, 2011) and continue to relate in adulthood (e.g., Kliegel, Mackinlay, \& Jäger, 2008; West \& Craik, 2001). Finally, from a neuropsychological standpoint, studies show that patients with cerebral lesions in areas associated with EF (mainly the frontal cortex) also show deficits in PM (e.g., Burgess, Alderman, Volle, Benoit, \& Gilbert, 2009; Crews, He, \& Hodge, 2007; Okuda et al., 1998; Shallice \& Burgess, 1991; Sowell, Delis, Stiles, \& Jernigan, 2001; Zamroziewicz et al., 2017). In view of the increasing evidence of a strong association between EF and PM, Mahy et al. (2014a) proposed the Executive Framework of PM Development, in which they suggest how the different EF contribute to forming, retaining, retrieving and performing an intention. They conclude that the "ability to flexibly modify thought and action is key to successfully remembering to fulfill one's intentions" (p. 307).

Despite the considerable number of studies linking EF to PM, to this day, many issues remain unresolved, particularly regarding the association between the two cognitive domains during childhood. Table 1 lists the currently available studies that have examined the relation of EF and PM in children (for studies on adults, see Azzopardi, Auffray, \& Kermarrec, 2017; Gonneaud et al., 2011; Schnitzspahn, Stahl, Zeintl, Kaller, \& Kliegel, 2013; Zuber, Kliegel, \& Ihle, 2016). First, Table 1 illustrates that although most studies agree on the existence of a link between EF and PM, so far, there is no consensus on how the three EF are specifically associated to the different PM types. For example, looking at children's nonfocal PM, Table 1 shows that Spiess, Meier, and Roebers (2015) found a significant association with shifting and updating but not with inhibition, whereas Mahy et al. (2014b) as well as Yi et al. (2014) present the exact opposite pattern of results. Similarly, inconsistent correlational patterns are observed for focal and time-based PM (again, see Table 1). 
Table 1

Overview of studies that have examined the link of executive functioning to PM performance (ordered by PM task type and author names).

\begin{tabular}{|c|c|c|c|c|}
\hline PM task type & Study & Age & Significant link found to & No significant link found to \\
\hline \multirow[t]{5}{*}{ Focal } & Ford et al. (2012) & $4-6$ & Inhibition, Working Memory & - \\
\hline & Mahy and Moses (2011) & $4-6$ & Working Memory & Inhibition \\
\hline & Shum et al. (2008) & $8-13$ & $\begin{array}{l}\text { Inhibition, Shifting, Working } \\
\text { Memory }\end{array}$ & - \\
\hline & $\begin{array}{l}\text { Williams, Boucher, Lind, and Jarrold } \\
\text { (2013) }\end{array}$ & $9-12$ & - & Shifting \\
\hline & Atance and Jackson (2009) & $3-5$ & Inhibition & - \\
\hline \multirow[t]{5}{*}{ Non-focal } & Causey and Bjorklund (2014) & $3-4$ & EF sum-score of EF & - \\
\hline & Mahy et al. (2014a) & $4-5$ & Inhibition & Shifting, Working Memory \\
\hline & $\begin{array}{l}\text { Mahy, Mazachowsky, and Pagobo } \\
\text { (2018) }\end{array}$ & $4-6$ & Inhibition & - \\
\hline & Spiess et al. (2015) & $7-9$ & Shifting, Updating & Inhibition \\
\hline & Yi et al. (2014) & $4-11$ & Inhibition & Shifting, Working Memory \\
\hline \multirow[t]{6}{*}{ Time-based } & Geurten et al. (2016) & $4,6,9$ & sum-score of EF & - \\
\hline & Kerns (2000) & $6-12$ & $\begin{array}{l}\text { Inhibition, Shifting, Working } \\
\text { Memory }\end{array}$ & - \\
\hline & Kretschmer et al. (2014) & $5-8$ & Working Memory & Inhibition \\
\hline & Mackinlay et al. (2009) & $7-12$ & Shifting, Working Memory & - \\
\hline & Mäntylä et al. (2007) & $8-12$ & Inhibition, Updating & Shifting \\
\hline & Voigt et al. (2014) & $5-14$ & Updating & - \\
\hline \multirow{2}{*}{$\begin{array}{l}\text { Overall PM (Sum score of different PM } \\
\text { tasks) }\end{array}$} & Robey et al. (2014) Robey et al. (2014) & $14-15$ & Inhibition, Shifting & Working Memory \\
\hline & Yang et al. (2011) & $7-12$ & Inhibition, Working Memory & - \\
\hline
\end{tabular}

Note. Age $=$ participants' age in years.

Second, Table 1 also shows that thus far, all studies have assessed a single PM task type at a time - or, if multiple PM tasks were administered, performance was subsequently combined into composite scores, preventing specific conclusions regarding the differential association of EF and PM by task type. Similarly, many studies have only assessed some (instead of all three) EF. This somewhat fragmented evaluation of EF and PM may further contribute to the incoherent overall associative pattern between the two domains: as all EF are strongly interrelated and share certain lower-level attentional processes (e.g., Shallice \& Burgess, 1996; Stuss \& Alexander, 2000), observed correlations with PM might partly be driven by underlying, more general attentional resources (e.g., Friedman \& Miyake, 2017; Gade, Schuch, Druey, \& Koch, 2014; Koch, Gade, Schuch, \& Philipp, 2010). In sum, it remains an open question whether there are specific, differential associations between the three EF and focal, nonfocal and time-based PM.

\subsection{The current study}

The main goal of the present study was to gain a clearer understanding of the role of the three EF in predicting children's PM performance in focal, nonfocal, and time-based tasks when age is considered simultaneously. In view of the important inconsistencies, past findings alone do not allow for clear a priori predictions regarding the association between EF and PM. Thus, for the present study, hypotheses were derived from previous findings as well as from conceptual theories of EF and PM.

As mentioned above, executive and prospective abilities start to develop at preschool and peak toward the beginning of adulthood. However, from a developmental standpoint, research suggests that middle childhood represents a particularly interesting period to study the relation of EF and PM (e.g., Cottini, Basso, \& Palladino, 2018). Both domains undergo crucial changes during this period of life (e.g., Best \& Miller, 2010; Best, Miller, \& Jones, 2009; Kliegel et al., 2013; Mahy et al., 2014a; Mahy \& Munakata, 2015) and improvements in EF over middle childhood lead to children becoming increasingly accurate in performing prospective tasks (e.g., Mackinlay et al., 2009; Smith, Bayen, \& Martin, 2010; Spiess et al., 2015; Spiess, Meier, \& Roebers, 2016; Yang, Chan, \& Shum, 2011). Specifically, research on EF suggests that inhibitory resources may develop earlier in childhood compared to shifting and updating (for reviews, see Best et al., 2009; Hughes, 2011). As focal PM is thought to most strongly rely on inhibition, this may (partially) explain why children typically succeed at focal tasks earlier and better compared to nonfocal and time-based tasks. Similarly, ageeffects are typically larger on nonfocal and time-based tasks, which may be the result of their higher demand on shifting and updating resources (Kliegel et al., 2013; Nigro et al., 2002).

To further investigate this, the current study aimed at evaluating executive and prospective abilities in 6- to 11-year old children and to examine developmental differences between focal, nonfocal, and time-based PM. In view of previous findings, we expected that EF in general would correlate with age, and that age would explain a significant portion of variance on nonfocal and time-based PM performance, but not on focal PM performance. Further, we expected that inhibition would be the EF that starts earliest to contribute to PM.

In terms of specific predictions on the involvement of particular EF in PM, successfully remembering to perform a prospective task represents a series of complex challenges: it involves multiple higher level processes such as elaborating a plan, forming an intention, maintaining and refreshing the intention, and executing it at the appropriate time (Kliegel, Martin, McDaniel, \& Einstein, 2002; Kvavilashvili \& Ellis, 1996). In the context of this task analysis, previous studies show that updating is required for several of these 
processes, such as solving complex tasks, making plans, and refreshing working memory (e.g., Diamond, 2013; Engle, 2002; Passolunghi \& Pazzaglia, 2005). As a consequence, we expected that updating resources form a more general factor supporting PM and should therefore predict children's performance on all three PM tasks.

In addition, a further challenge of PM tasks is that they have to be performed while one is occupied with another task. In eventbased tasks, the appropriate moment to perform the PM task is indicated by a (focal or nonfocal) PM cue. In focal tasks, the literature suggests that the detection of the target-cue can more strongly rely on automatic processes, as it involves processes similar to the ones deployed by the ongoing task (again, see the multiprocess framework by McDaniel \& Einstein, 2000). In contrast, nonfocal tasks have less overlap between the processing required for the ongoing task and the detection of the PM cue. Therefore, in addition to performing the ongoing task, individuals have to strategically monitor for the appearance of the nonfocal PM cue. Similarly, in timebased tasks, in addition to performing the ongoing task, participants have to continuously monitor the progression of time in order to correctly detect the target-time. Thus, both nonfocal and time-based PM tasks require individuals to continuously reallocate attentional resources between two different tasks sets, that is, switching between performing the ongoing task and monitoring for the target-cue/-time. As a consequence, we expected that shifting resources should predict children's performance on the nonfocal as well as the time-based, but not the focal PM task.

Further, after successfully detecting the target-cue/-time, one has to be able to refrain from performing the ongoing task and execute the PM task instead. This might be particularly challenging in event-based tasks, as the PM cue appears at intervals of unpredictable, random length. Thus, we expected that performance on focal and nonfocal PM tasks would be predicted by children's inhibitory resources. In contrast to event-based tasks, the target-time to perform the PM task is highly regular and predictable in timebased PM tasks (e.g., remembering to push a specific button every $60 \mathrm{~s}$ ). Specifically, by monitoring the progression of time (e.g., by frequently checking the clock), one can estimate when the PM task will have to be performed (which is not possible in event-based tasks). Thus, it is plausible that with the target-time approaching, participants could progressively disengage from the ongoing task and set up preparatory processes in order to perform the PM task at target-time. In that case, individuals might not need to actively inhibit performing the ongoing activity as soon as the target-time actually occurs. Therefore, we expected that performance on the time-based task would not be predicted by children's inhibitory abilities. Further, if individuals indeed prepare to perform the timebased PM task, it is probable that they allocate fewer resources to the ongoing task and more resources toward the execution of the PM task as the PM target-time approaches. As a consequence, performance on the ongoing task should progressively decrease as the target-time approaches.

In this context, previous studies have examined the frequency of time-monitoring as a function of time (Ceci \& Bronfenbrenner, 1985; Kerns, 2000; Mackinlay et al., 2009; Mantyla, Carelli, \& Forman, 2007; Voigt, Aberle, Schonfeld, \& Kliegel, 2011; Voigt et al., 2014). Generally, they have found that monitoring significantly increases as PM target-times approach. However, so far it is unknown whether this increase in time-monitoring also impacts ongoing task performance. We argue that, if children continuously disengage from the ongoing task to prepare performing the PM task, they should show worse ongoing task performance on the time-based task as PM target times approach. Thus, we expected that ongoing task cost (i.e., ongoing task errors) would increase as PM target-times approach. Regarding the distribution of attentional reallocation processes, Voigt et al. (2014) suggested that future studies should examine whether the shift of attention away from the ongoing and toward the PM task would be reflected in a U-shaped (quadratic calibration), J-shaped (exponential increase), or linear (constant increase) pattern of ongoing task costs. To follow up on this open question, we aimed to further investigate the pattern of ongoing task costs over time.

In sum, the present study was the first to investigate all three core EF as well as all three types of PM tasks (focal, non-focal, timebased) in one group of school-aged children. Its main goal was to investigate the differential association between EF and different PM types over the ages 6- to 11-years. Based on a conceptual task analysis of the processes involved in PM, our first hypothesis was that (1) age would correlate with the three EF and that - when considered separately - age would predict performance on nonfocal and time-based but not on focal PM. Next, our main hypotheses were that when all variables are considered simultaneously: (2) children's focal PM performance would be predicted by inhibition and updating (but not shifting), (3) nonfocal PM performance would be predicted by all three EF, and (4) time-based performance would be predicted by shifting and updating (but not inhibition). Finally, our last hypothesis was that (5) on the time-based PM task children would make more ongoing task errors close to target-times because they are investing fewer resources in the ongoing task as the PM target time approaches.

\section{Method}

\subsection{Participants}

Two hundred and twenty-two children aged 6 to 11 years participated in the study. Ten children scored below two standard deviations of their age-group norms on fluid or crystallized intelligence measures (subtests "Matrices" and "Vocabulary" of the WISCIV; Wechsler, 2004) and were thus excluded from subsequent analyses. None of the remaining participants reported a history of neuropsychopathology or psychopathology (evaluated by caregivers through self-assessment questionnaires). Further, all of the remaining children were either native French speakers or, if French was not their first language, they had fluent proficiency. Thus, the final sample consisted of 212 children $\left(M_{\text {age }}=8\right.$ years; 3 months, $S D=1$ year; 5 months), 109 of which were girls ( $52 \%$; there was no significant difference in age between the two gender groups). Table 2 displays number of children and mean age per age group of the final sample. All children and their caregivers gave informed consent. All procedures were approved by the ethics committee at the University of Geneva. 
Table 2

Means (and standard deviations) and between-age-group ANOVAs of outcome measures.

\begin{tabular}{|c|c|c|c|c|c|c|c|c|}
\hline & $N$ & Age & Inhibition & Shifting & Updating & Focal PM & Nonfocal PM & Time-based PM \\
\hline Overall & 212 & $8 ; 3(1 ; 5)$ & $.81(.14)$ & $385.13(323.28)$ & $.35(.24)$ & $.75(.28)$ & $.63(.30)$ & $.39(.34)$ \\
\hline 6-years & 26 & $6 ; 2(0 ; 3)$ & $.81(.18)$ & $434.23(344.28)$ & $.29(.24)$ & $.68(.24)$ & $.48(.34)$ & $.23(.23)$ \\
\hline 7-years & 55 & $7 ; 0(0 ; 4)$ & $.78(.15)$ & $432.47(397.15)$ & $.29(.22)$ & $.75(.31)$ & $.64(.30)$ & $.38(.28)$ \\
\hline 8-years & 40 & $8 ; 0(0 ; 4)$ & $.77(.14)$ & $497.68(327.17)$ & $.23(.20)$ & $.68(.35)$ & $.59(.34)$ & $.25(.31)$ \\
\hline 9-years & 43 & $9 ; 1(0 ; 3)$ & $.84(.15)$ & $341.85(252.40)$ & $.47(.26)$ & $.79(.21)$ & $.67(.23)$ & $.49(.38)$ \\
\hline 10-years & 36 & $10 ; 2(0 ; 3)$ & $.86(.11)$ & $261.46(196.23)$ & $.44(.21)$ & $.82(.21)$ & $.71(.26)$ & $.50(.36)$ \\
\hline 11-years & 12 & $10 ; 10(0 ; 3)$ & $.90(.07)$ & $245.76(256.20)$ & $.51(.23)$ & $.72(.29)$ & $.72(.30)$ & $.48(.42)$ \\
\hline$F$ & & & 3.12 & 2.89 & 7.12 & 1.45 & 2.32 & 3.62 \\
\hline$p$ & & & .010 & .015 & .000 & .209 & .045 & .004 \\
\hline
\end{tabular}

Note. $N=$ number of participants; Age = age in years; months.

\subsection{Measures}

\subsubsection{Prospective memory tasks}

We used three established tasks that have been frequently used in studies on PM development in school children.

Focal PM: Size Sorting Task (adapted from Mahy et al., 2014b). For the focal PM task, children worked on a computerized card sorting game. As ongoing task, children were asked to sort a series of images that were presented within a square. For each image, they had to decide whether it depicted a large or a small object (by pushing the left/right arrow key). Images in the large condition showed objects that were large both in reality as well as in size on the screen (i.e., a cupboard, a car, a refrigerator). Small items were small both in reality as well as on the screen, as they were set to a maximum size of $1 / 3$ of the height or width of the square (i.e., an alarm clock, a toothbrush, a ring). The $P M$ task consisted of remembering to push the white button (attached to the "ctrl"-key) whenever the image was an animal. Animal images appeared in both the large and the small format.

Children began with 16 practice trials of the ongoing task only (and a second 16 practice trials if their accuracy was below 60\%). Next, the experimenter introduced the $P M$ task. Specifically, children were instructed to refrain from naming the card but pushing the white button instead whenever an animal image appeared. After the PM task was explained, children were asked to draw a castle during a 3-min delay interval. After this delay interval, children were told that they now had to do the sorting task as explained before. For each trial, the stimuli remained on the screen until a response was given or until $3500 \mathrm{~ms}$ had elapsed. A fixation cross located at the horizontal and vertical center of the screen was presented for $1000 \mathrm{~ms}$ between trials. There were three test blocks of 28 trials each, with a one minute break after each block during which children could pause before starting to work on the next block. The PM cues were pseudo-randomly presented on the 12th and 27th trial for the first, on the 14th and 21st trial for the second, and on the 7th and 23rd trial on the third block. The remaining 26 trials of the ongoing task in each block randomly showed small and large stimuli. The dependent variable was the number of correctly detected PM targets divided by six to yield an accuracy score (PM scores ranging from 0 to 1 ). At the end of the task, children were asked to describe the task instructions to assure they remembered the $P M$ task retrospectively. Regardless of their PM performance, all participants were able to recall the PM task instructions.

Nonfocal PM: Dots Task (adapted from Mahy, Mohun, Muller, \& Moses, 2016)(adapted from Mahy, Mohun, Muller, \& Moses, 2016). In this nonfocal PM task, a rectangular square was displayed on the screen showing household items or animals at its center. In addition, on every trial either a rock or a diamond could appear above or below the central image. The ongoing task was to indicate whether they wanted to collect or discard the object displayed above/below the central stimulus, by pushing the green button (left arrow key) to collect the diamonds and the red button (right arrow key) to discard the rocks. The $P M$ task consisted of remembering to push the white button ("ctrl"-key) when the image depicted an animal.

The procedure was similar to the focal task: Children first practiced on 16 trials of the ongoing task and received an additional 16 practice trials if accuracy was below $60 \%$ which was followed by the $P M$ instructions and a 3-min drawing session during the delay phase. Then children began the ongoing task. There were two test blocks of 63 trials, with a one minute break after the first block during which children could rest. The PM cues were presented on the 15th, 36th and 60th trial for the first block and on the 11th, 34th and 55th trial for the second block. The remaining 60 trials of ongoing task in each block changed randomly between diamond and rock trials. Task presentation specifications were the same as for the focal task. The dependent variable was the number of correctly detected PM targets divided by six to yield an accuracy score (PM scores ranging from 0 to 1 ). At the end of the experiment, children were asked to describe the task instructions to ensure they remembered the PM task retrospectively. All participants were able to recall the PM task instructions.

Time-based PM: Swiss Cruiser. The time-based PM task was embedded in a car driving video game (Kliegel et al., 2013; Kretschmer, Voigt, Friedrich, Pfeiffer, \& Kliegel, 2014; Voigt et al., 2011). For the ongoing task, children had to maneuver a car on a 2-dimensional road of three parallel lanes by using the left and right arrow keys (they were able to maneuver the car on the horizontal left-/rightbut not the vertical up-/down-axis). Children gained points by avoiding hitting other cars on the road. After a 1-min practice session of the ongoing task, the $P M$ task was presented: in addition to driving the vehicle, children would have to remember to refuel the car (which was possible every $50 \mathrm{~s}$ within a time-interval of $10 \mathrm{~s}$ ). By pushing the "c"-button on the keyboard, they could display a fuel gauge in the left lower corner of the screen. When the fuel gauge showed that the tank was less than a quarter full (indicated by a red area on the gas display between 50 and 60 s), children could refuel by hitting the "space"-bar, which gave them additional points. If 
children forgot to perform the PM task, the tank was refilled automatically every $60 \mathrm{~s}$. After a delay phase of three minutes, during which children could draw freely, they performed on the ongoing and PM task for four minutes (i.e., four PM target times). At the end of the experiment, children were asked to describe the task instructions to ensure they remembered the PM task retrospectively which all children were able to do. The time-based PM outcome measure used was the number of refuels divided by four to yield an accuracy score. To assess ongoing task performance in relation to PM target-times, we examined participants' car crash rates (i.e. number of crashed cars). Specifically, we divided each refuel interval (i.e. the time between two refuels, $\mathrm{I}_{1}, \mathrm{I}_{2}, \mathrm{I}_{3}$, and $\mathrm{I}_{4}$ ) into four sub-quartiles (e.g., $\mathrm{I}_{1} \mathrm{Q}_{1}, \mathrm{I}_{1} \mathrm{Q}_{2}$, etc.). ${ }^{1}$ For each sub-quartile, the car crash rate was calculated. Next, car crash rates were averaged for each subquartile over all refuel-intervals. ${ }^{2}$ The final ongoing task cost measures per quartile (i.e. car crash $Q_{1}, Q_{2}, Q_{3}, Q_{4}$ ) thus represent the average number of cars that were crashed during a particular quartile.

\subsection{Executive function tasks}

As for PM, we used three established EF tasks that have been frequently used in studies on EF development in school children. Updating: Spatial N-back Task. For the updating task, we used an adapted version of a classical spatial 2-back task (e.g., Jaeggi, Buschkuehl, Jonides, \& Shah, 2011). For this task, a 3 by 2 grid was displayed on the screen and on every trial, a cartoon character randomly appeared in one of the six cells. Children were asked to indicate whether the character's current location was identical to or different from the location 2 trials before by pushing the green button (left arrow key) when the location was identical and the red button (right arrow key) when it was different. Children first practiced on a 17-trial block, which was repeated if the performance was below $60 \%$. This was followed by the actual updating task, which consisted of five blocks of 17 trials in which 5 trials were hits (i.e., character in the same location as 2 trials before). For each trial, a fixation cross was presented in the center of the screen for $1000 \mathrm{~ms}$, which was followed by the display of the grid with the comic character for a maximum response time of $4000 \mathrm{~ms}$. The outcome measure used was the proportion of correctly detected hits minus the proportion of false alarms on non-hit trials (for similar scoring, see Jaeggi et al., 2010).

Inhibition: Go-NoGo Task (adapted from Schulz et al., 2007). Children were instructed to hit the "space"-bar as quickly as possible if an animal picture appeared on the screen (Go stimuli, 75\% of all trials) except for pictures that showed a bird where no response was to be made (NoGo stimulus, $25 \%$ of all trials). On each trial, an animal stimulus was presented at the central location of the screen for $1000 \mathrm{~ms}$, which was followed by a maximum $3000 \mathrm{~ms}$ blank screen if no response was given. Each stimulus was preceded by a fixation cross which was randomly presented between 1250 and 1750 ms. Children performed a 16 trial practice block, followed by a second practice block if the performance was below $60 \%$. Then they performed a single block of 96 trials for the task. The outcome measure was the proportion of correctly inhibited NoGo trials (for similar scoring see e.g., Berlin \& Bohlin, 2002; Thorell, Lindqvist, Nutley, Bohlin, \& Klingberg, 2009).

Shifting: Dots \& Triangles Task (e.g., Huizinga, Dolan, \& van der Molen, 2006). For the shifting task, we used an adapted version of the classical dots and triangles paradigm comprising two single task blocks (Task A and Task B) and a mixed-task block. For task A, children were asked to indicate whether there were more dots on the left or the right half of a $4 \times 4$ grid by pushing the left or right arrow key. On task B, children had to decide whether there were more triangles in the top or bottom half of the grid, by pushing the up and down arrow keys. Both single task blocks were separated in three parts: 10 practice trials, another 10 practice trials if the correct response rate of the first practice was below $60 \%$, and then 40 experimental trials of the single task. Children started by performing blocks A and B (counter-balanced). The two single-task blocks were followed by the mixed-task block, where the actual shifting task was conducted (21 practice trials, 21 re-practice trials, 81 experimental trials). Here, children had to shift between task A and task B every four trials (i.e., trials 1 to 4 displayed grids with dots, trials 5 to 8 displayed triangles, trials 9 to 12 displayed dots, etc.). For each trial, the stimuli remained on the screen until a response was given, with a maximum response time of $4000 \mathrm{~ms}$. A fixation-cross located at the horizontal and vertical center of the screen was presented variably between 500 and $750 \mathrm{~ms}$. The outcome measure used was the reaction time shifting cost, which was the mean reaction time on correct shift trials (i.e., trials on which children had to shift from one to the other task) minus the mean reaction time on correct non-shift trials (i.e., trials on which children had to perform the same task as on the previous trial).

\subsection{Procedure}

Children were tested in two individual sessions of about $45 \mathrm{~min}$, separated by approximately one week. Order of task presentation was pseudo-randomized: the first session addressed time-based PM, updating and focal PM, whereas the second session consisted of inhibition, shifting, and nonfocal PM. All testing sessions were conducted by two experimenters in a quiet environment where children were not distracted.

\footnotetext{
${ }^{1}$ For example, if a participant pushed the refuel button at $52 \mathrm{~s}$ in the first refuel interval $\left(=\mathrm{I}_{1}\right)$, this would results in four sub-intervals of $(52 / 4=)$ $13 \mathrm{~s}: \mathrm{I}_{1} \mathrm{Q}_{1}$ (hits 0 to $13 \mathrm{~s}$ ), $\mathrm{I}_{1} \mathrm{Q}_{2}$ (hits from 13 to $26 \mathrm{~s}$ ), $\mathrm{I}_{1} \mathrm{Q}_{3}$ (hits from 26 to $39 \mathrm{~s}$ ) and $\mathrm{I}_{1} \mathrm{Q}_{4}$ (hits from 39 to $52 \mathrm{~s}$ ).

${ }^{2}$ For example, the car crash rate averaged for all four first quarters (= car crash rate $Q_{1}$ ) would be the average of $I_{1} Q_{1}, I_{2} Q_{1}, I_{3} Q_{1}$, and $I_{4} Q_{1}$.
} 
Table 3.1

Raw (and partial) correlations between prospective memory and executive functions measures.

\begin{tabular}{|c|c|c|c|c|}
\hline \multirow[t]{2}{*}{ Measures } & \multirow[t]{2}{*}{ Age } & \multicolumn{3}{|c|}{ Prospective memory } \\
\hline & & Focal & Nonfocal & Time-based \\
\hline Age & - & .11 & $.19^{k * *}$ & $.24^{* * * *}$ \\
\hline Inhibition & $.19^{* * *}$ & $.24^{* * * *}\left(.21^{* * *}\right)$ & 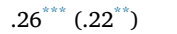 & $.14(.10)$ \\
\hline Shifting & $-.20^{* k}$ & $-.11(-.05)$ & $-.21^{* *}\left(-.16^{*}\right)$ & $-.20^{* k 3}(-.12)$ \\
\hline Updating & $.31^{k * m * k}$ & $.24^{k * * k}\left(.22^{* *}\right)$ & $.26^{* * * x}\left(.16^{* *}\right)$ & $.27^{\text {k**** }}\left(.18^{*}\right)$ \\
\hline
\end{tabular}

Note. Age in years. Partial correlations controlling for age, fluid intelligence and crystallized intelligence are shown in parentheses. All tests are twotailed.

$$
\begin{aligned}
& * p \leq .05 \\
& * * p \leq .01 \\
& * * * p \leq .001
\end{aligned}
$$

\section{Results}

\subsection{Descriptive statistics and correlations}

Descriptive statistics of the outcome measures are shown in Table 2. Performance did not differ on any of the measures by participants' gender ( $p$-values of all $t$-tests $>.05$ ), thus we did not include gender as variable in subsequent analyses. Table 3.1 illustrates raw and partial correlations (controlling for age, fluid intelligence, and crystallized intelligence) among the variables of interest. Age was significantly correlated to children's performance on nonfocal PM, time-based PM, inhibition, shifting, and updating, but was uncorrelated with focal PM $(p=.93)$. After controlling for age, fluid intelligence and crystallized intelligence, focal PM remained significantly correlated to inhibition and updating, nonfocal PM was correlated to all measures of EF, and time-based PM was only significantly correlated to updating. Table 3.2 illustrates age-specific correlations among the variables of interest per age group (6-7, 8-9 and 10-11 year olds).

\subsection{Age and executive functioning as predictors of $P M$}

In order to examine the age-related development of PM, and to assess the distinct contribution of the three EF to focal, nonfocal, and time-based PM performance after controlling for age-related changes in PM capacities, we conducted three separate hierarchical linear regression analyses (Table 4). The first regression revealed that age as single predictor did not significantly explain variance in focal PM performance. However, adding the three EF measures in second step significantly improved the prediction model. When all factors were considered simultaneously, inhibition and updating (but not shifting) significantly predicted focal PM performance.

The second regression indicated that age as single predictor explained a significant portion of variance in nonfocal PM capacities. When EF measures were entered with age in a second step, inhibition, shifting and updating (but not age) were significant predictors of nonfocal PM. Adding the EF measures in step 2 significantly improved the amount of variance explained by the model.

Table 3.2

Correlations between prospective memory and executive functions measures separated per age group.

\begin{tabular}{llll}
\hline \multirow{2}{*}{ Measures } & \multicolumn{2}{l}{ Prospective memory } & \\
\cline { 2 - 4 } & Focal & Nonfocal & Time-based \\
\hline 6-7 year olds $(n=81)$ & .20 & & .18 \\
Inhibition & .21 & $.28^{* * *}$ & $-.29^{* * *}$ \\
Shifting & .14 & -.18 & .19 \\
Updating & & .22 & .12 \\
8-9 year olds $(n=83)$ & $.32^{* * *}$ & & -.07 \\
Inhibition & .12 & $.23^{* *}$ & $.32^{* *}$ \\
Shifting & $.24^{*}$ & -.12 & \\
Updating & & $.23^{* *}$ & -.06 \\
10-11 year olds $(n=48)$ & .00 & & -.11 \\
Inhibition & -.23 & .10 & .14 \\
Shifting & $.36^{*}$ & $-.36^{* *}$ & .22 \\
Updating & & &
\end{tabular}

Note. All tests are two-tailed.

$$
\begin{aligned}
& * p \leq .05 . \\
& * * p \leq .01 \\
& * * * p \leq .001
\end{aligned}
$$


Table 4

Multiple regression analyses of age and executive functions predicting prospective memory and time-monitoring.

\begin{tabular}{|c|c|c|c|c|c|}
\hline Variable & $\beta$ & $t$ & $p$ & $R^{2}$ & $\Delta R^{2}$ \\
\hline \multicolumn{6}{|l|}{ Focal PM } \\
\hline Step 1 & & & & .01 & .01 \\
\hline Age & .11 & 1.50 & .14 & & \\
\hline Step 2 & & & & .10 & $.09^{* * * * x}$ \\
\hline Age & -.01 & -0.07 & .94 & & \\
\hline Inhibition & .20 & 2.89 & $.00^{* k \times k}$ & & \\
\hline Shifting & -.06 & -0.86 & .39 & & \\
\hline Updating & .20 & 2.72 & $.01^{* * *}$ & & \\
\hline \multicolumn{6}{|l|}{ Nonfocal PM } \\
\hline Step 1 & & & & .03 & $.04^{\text {w***en}}$ \\
\hline Age & .19 & 2.63 & $.01^{* k * k}$ & & \\
\hline Step 2 & & & & .14 & $.11^{\text {w*ne }}$ \\
\hline Age & .06 & 0.86 & .39 & & \\
\hline Inhibition & .21 & 3.00 & $.00^{* * *}$ & & \\
\hline Shifting & -.15 & -2.12 & $.04^{*}$ & & \\
\hline Updating & .18 & 2.50 & $.01^{\text {wik }}$ & & \\
\hline \multicolumn{6}{|l|}{ Time-based PM } \\
\hline Step 1 & & & & .06 & $.06^{m * * * x}$ \\
\hline Age & .24 & 3.26 & $.00^{\operatorname{sicksex}}$ & & \\
\hline Step 2 & & & & .12 & $.06^{* * x}$ \\
\hline Age & .14 & 1.85 & .07 & & \\
\hline Inhibition & .07 & 0.95 & .35 & & \\
\hline Shifting & -.13 & -1.74 & .08 & & \\
\hline Updating & .19 & 2.49 & $.01^{*}$ & & \\
\hline Step 3 & & & & .52 & $.40^{* * * * x}$ \\
\hline Age & .08 & 1.29 & .20 & & \\
\hline Inhibition & .09 & 1.63 & .11 & & \\
\hline Shifting & -.01 & -.21 & .83 & & \\
\hline Updating & .10 & 1.68 & .09 & & \\
\hline Time-monitoring & .66 & 11.73 & $.00^{\text {tithen }}$ & & \\
\hline \multicolumn{6}{|l|}{ Time monitoring } \\
\hline Step 1 & & & & .03 & .03 \\
\hline Age & .18 & 2.38 & $.02^{* \prime}$ & & \\
\hline Step 2 & & & & .09 & $.06^{*}$ \\
\hline Age & .10 & 1.32 & .19 & & \\
\hline Inhibition & -.03 & -0.40 & .69 & & \\
\hline Shifting & -.18 & -2.36 & $.02^{*}$ & & \\
\hline Updating & .14 & 1.83 & .07 & & \\
\hline
\end{tabular}

$* p \leq .05$.

$* * p \leq .01$.

$* * * p \leq .001$.

Note. Age $=$ Age in years. Time-monitoring was calculated in terms of frequency of clock-checking in the time-based PM task (i.e. how often children pushed the button to display the fuel gauge level).

The third regression showed that, when considered separately, age explained a significant portion of the variance of time-based PM. However, adding EF measures in a second step again significantly increased the explained variance. In that model, only updating was a significant predictor of time-based PM.

\subsection{Ongoing task performance on time-based task according to PM target-time}

We conducted a repeated measures ANOVA to examine whether ongoing task car crash rates (errors) on the time-based task were higher close to PM target times (see Fig. 1). Results show that there was a significant effect of time on ongoing task car crash rate, $F(3$, $459)=6.609, p<.001, \eta^{2}=.04$. They further show that the linear effect of time on car crash rate was significant $(p<.001)$, and that there was no significant quadratic effect $(p=.21)$. Subsequent analyses revealed significant differences between quartiles $\mathrm{Q}_{1}$ and $\mathrm{Q}_{2}(t(153)=-3.65, p<.001)$, and between $\mathrm{Q}_{1}$ and $\mathrm{Q}_{4}(t(153)=-3.99, p<.001)$, but no significant difference between $\mathrm{Q}_{3}$ and $\mathrm{Q}_{4}(t(153)=-1.71, p=.089)$, nor between $\mathrm{Q}_{2}$ and $\mathrm{Q}_{3}(p>.10)$.

\subsection{Follow-up analysis on children's time-monitoring during time-based PM task}

We initially hypothesized that shifting resources would predict children's performance on the nonfocal as well as the time-based task: both tasks require participants to strategically monitor for the PM target-cue/-time, which should be facilitated by one's ability to flexibly reallocate attentional resources between the ongoing task and the PM task. Although shifting was a significant predictor of 


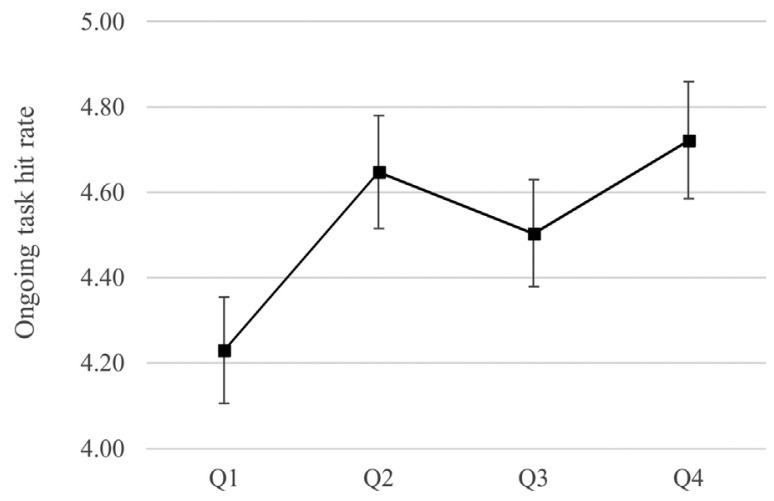

Fig. 1. Means and standard errors of the ongoing task car crash rates (errors), separated by quartiles $\left(Q_{1}, Q_{2}, Q_{3}, Q_{4}\right)$.

nonfocal PM, it did not significantly predict time-based PM $(p=.08)$. As time-monitoring seems essential for successful performance on time-based tasks, in follow-up analyses we wanted to explore children's time-monitoring in more detail. Specifically, we aimed to examine whether time-monitoring predicted successful time-based PM, and if so, how EF contributed to children's time-monitoring in particular.

To do so, we measured time-monitoring in terms of frequency of clock-checking in the time-based PM task (i.e., how often children pushed the button to display the fuel gauge level). Correlations showed that time-monitoring was significantly associated with children's age $(r(180)=.18, p=.018)$, as well as their performance on the time-based PM task $(r(182)=.69, p<.001)$, indicating that older children monitored time more often, and that the frequency of monitoring was strongly associated with successful time-based PM performance. Thus, we included time-monitoring as additional predictor of time-based PM in a third step of our hierarchical linear regression analyses (see Table 4). Adding time-monitoring to this final regression model considerably increased the total amount of explained variance further.

As time-monitoring was found to be a crucial predictor in children's time-based PM performance, next, we additionally conducted a hierarchical linear regression analyses in order to examine how executive resources would predict time-monitoring above and beyond age (see Table 4). In a first step, if age was considered separately, it significantly predicted time-monitoring. However, when all factors were considered together, time-monitoring was only significantly predicted by children's shifting performance.

\section{Discussion}

The present study examined the differential association of the three EF (updating, inhibition, and shifting) with different types of prospective memory (focal, nonfocal, and time-based) after controlling for age in a group of two hundred and twelve school-aged children. Overall, results show that when all variables were considered simultaneously, age did not significantly predict children's PM performance. Instead, children's PM performance on all PM task types was predicted by their updating resources, whereas inhibition additionally predicted focal and nonfocal performance, and shifting specifically contributed to children's nonfocal PM performance.

In detail, regarding our first hypothesis the current findings revealed that the three EF capacities increased over middle childhood and that age was a significant predictor of a nonfocal and time-based, but not of focal PM. In contrast, as age did not significantly explain any variance in children's performance on any of the prospective tasks when considered alongside children's executive capacities, our findings suggest that these EF are indeed critical in explaining age-related increases in PM. From a developmental perspective, these findings are in line with previous studies that show age-related increments in PM and in EF (Aberle, Rendell, Rose, McDaniel, \& Kliegel, 2010; Best \& Miller, 2010; Carlson \& Moses, 2001; Davidson, Amso, Anderson, \& Diamond, 2006; Kliegel \& Jäger, 2007). Similarly, they confirm that age-effects are typically larger on nonfocal and time-based versus focal tasks (e.g., Kliegel et al., 2013; Nigro et al., 2002), which seems to be the consequence of a differential EF deployment. Indeed, age-specific correlations suggest that inhibition may be a significant correlate of children's PM before updating becomes important. Our findings further corroborate the previous literature in underlining that developmental increases of executive resources (rather than age per se) lead to improvement of PM performance over childhood (e.g., Atance \& Jackson, 2009; Ford et al., 2012; Kerns, 2000; Wang et al., 2011).

Next, and more importantly, looking at the differential association of the three EF and the three PM tasks, data supported our second hypothesis that inhibition and updating would predict focal PM performance. This finding is in line with Ford et al. (2012) who found a positive association between inhibitory control and updating abilities and preschool children's focal PM performance. Further, it extends previous findings that observed the same pattern in adults (Zuber et al., 2016). By assessing PM in a large sample of school-aged children, the present findings therefore support previous studies suggesting that inhibition and updating underlie focal PM performance (e.g., Ford et al., 2012; Mahy \& Moses, 2011; Shum, Cross, Ford, \& Ownsworth, 2008). Further, they importantly contribute to the literature on the Multiprocess Framework (McDaniel \& Einstein, 2000), which has classified focal tasks as being mainly related to more automatically-driven bottom-up processes, needing little to no additional attentional control (e.g., Scullin, McDaniel, Shelton, \& Lee, 2010). We argue in line with the multiprocess framework that the detection of focal PM cues may primarily rely on lower-level processes and might therefore not specifically demand attentional control. However, and here we go beyond previous discussions of the multiprocess framework, our data suggests that even focal tasks deploy to a certain extent executive 
resources. Thus, we argue that it would be mainly the planning and the execution of the PM action that requires executive resources (also see Mahy et al., 2014a). Specifically, updating resources may be recruited to plan the prospective action, as well as to regularly refresh and recall instructions of the ongoing and the PM task. Further, inhibitory control seems to be deployed in interrupting the ongoing task (i.e., to refrain from treating the PM stimulus as an ongoing task stimulus) in order to execute the PM task instead.

Regarding our third hypotheses, results confirm that all three EF measures (updating, inhibition, and shifting) predicted nonfocal PM performance. As in focal tasks, nonfocal tasks seem to require inhibition to interrupt the ongoing task, and updating as more general resources involved in solving complex tasks, forming future intentions and refreshing different task instructions. As introduced above, nonfocal tasks differ from focal tasks in that the detection of the PM cue cannot rely on automatic/bottom-up resources, but that one would have to strategically monitor for the appearance of the nonfocal cue. Such strategic monitoring should specifically rely on shifting: in nonfocal tasks, participants have to continuously reallocate attentional resources between multiple task sets, namely, between performing the ongoing task and monitoring for the nonfocal PM cue. Our findings hereby further support the multiprocess framework, which states that because of the necessary cue-monitoring, compared to focal tasks, nonfocal tasks rely more strongly on strategically guided resources of attentional control. In this context, literature on the development of selective attention shows that having to simultaneously track multiple objects and having to process information details which are peripheral to the central stimulus demands is more difficult as this imposes a higher demand on strategic resources (e.g., Duncan, 1984; LangeKüttner, 2000; Remington, Cartwright-Finch, \& Lavie, 2014). Our data hereby adds to these findings, and suggests that this additional resource-demand may mainly concern attentional shifting resources, which is further in line with PM studies that found a link between shifting and nonfocal PM in children (e.g., Spiess et al., 2015) and adults (e.g., Zuber et al., 2016).

As for the fourth hypothesis, present data only partially supported our assumptions: as predicted, updating but not inhibition predicted children's performance on the time-based PM task. As in the other PM tasks, updating resources seem to be recruited so that children can maintain, refresh, and recall instructions of the ongoing and of the PM task. For time-based tasks updating might further be required to keep track of the progression of time (i.e., how frequently one checks the clock, how much time has elapsed since the last clock-check, how much time is left before the PM task has to be performed, etc.).

In addition, in our study, the attentional resource demands may have been particularly high for the time-based compared to the focal task: besides keeping track of the progression of time, having to navigate a moving car in a two-dimensional space requires a different attention system (where-system), which is still developing during school-age (see Klaver, Marcar, \& Martin, 2011; Parrish, Giaschi, Boden, \& Dougherty, 2005; Ungerleider \& Mishkin, 1982). This stands in contrast to the focal task, for which children mainly had to identify particular objects (what-system), a capacity that develops earlier and does not show age-effects during school-age (see Klaver et al., 2011; Parrish et al., 2005; Ungerleider \& Mishkin, 1982). This may further influence developmental differences between focal and time-based tasks.

Observed links between updating, and children's time-based PM are partially in line with previous studies that specifically found a significant association among these abilities (e.g., Kretschmer et al., 2014; Voigt et al., 2014). However, we further expected that shifting resources would predict time-based PM performance, which was not the case in our final regression model. We initially argued that the ability to shift between different task sets would be of particular importance in time-based tasks, as successful PM performance should strongly depend on regularly monitoring the progression of time, which requires repeated switches between the ongoing task and time-monitoring. Therefore, we conducted supplementary analyses to investigate whether time-monitoring predicted children's PM performance, and to examine the role of EF (and shifting in particular) in time-monitoring during time-based tasks. Results show that more frequent time-checking was a significant predictor of better prospective remembering above and beyond age and executive resources, and that time-monitoring was significantly predicted by children's shifting resources.

Taken together, although shifting was not a significant predictor of time-based PM performance in our initial analysis, these additional analyses indicate that shifting indeed is related to children's time-monitoring and that time-monitoring is highly predictive of successful time-based PM performance. As shifting and time-monitoring seem to be crucial processes in order to successfully perform a time-based PM task, one possible interpretation of the overall pattern is that shifting represents a critical ability allowing participants to switch attentional resources between the ongoing task and time-monitoring, that time-monitoring is essential in order to be able to perform the PM task at the appropriate time, but that shifting alone is less important in actually carrying out the prospective intention. Although our study gives first insights into the different processes required for and involved in performing time-based PM tasks, future studies will have to follow-up on this issue and establish in more detail during which phases of PM the different resources and strategies would be most strongly deployed (for more details on the four phase model of PM and the role of EF, see Kliegel et al., 2002; Kvavilashvili \& Ellis, 1996; Mahy et al., 2014a).

Finally, in line with our fifth hypothesis, children committed more ongoing task errors on the time-based task as target-times approached. This supports the idea that in time-based tasks participants might rely less on inhibitory control because the occurrence of the PM target is highly predictable. As a consequence, they could progressively disengage from the ongoing task (i.e. allocating less attentional resources toward the ongoing task) and prepare to perform the PM task at the target-time (i.e., allocating more resources toward time monitoring and toward the execution of the PM task itself). This novel finding has important conceptual implications regarding the distribution of attentional reallocation processes. In a previous study, Voigt et al. (2014) suggested that future studies should examine whether ongoing task costs would be reflected in a U-shaped (quadratic calibration), J-shaped (exponential increase), or linear (constant increase) pattern of ongoing task costs. Following up on this suggestion, our data shows that the linear trend (but not the quadratic) was significant. Thus, the present findings speak against a U-shaped pattern of costs, as the number of errors in the time interval right after the execution of the PM task was significantly lower than the number of errors in all other time-intervals. Similarly, our findings speak against a J-shaped pattern, as ongoing task errors followed a linear rather than an accelerated increase. Taken together, present findings sustain the idea that performing a time-based PM task allows participants to mentally "unload" the 
PM intention at the beginning of a delay interval and consequently reallocate more attentional resources to the ongoing task (as they know that right after executing the time-based PM task the next target-time will not occur for a certain time). Further, our data illustrates how the mental load of the PM intention then increases progressively, linearly as the next target-times approaches.

\subsection{Limitations and future directions}

Finally, there are several limitations to our study, which should be addressed by future research. First, a key question for developmental research is to investigate how the specific association between executive resources and different types of PM changes during childhood. Although the present findings suggest that inhibition contribute to PM before other EF, future studies should assess both cognitive domains in a wider age-range with larger power, so that age-band specific analyses become possible. Such analysis may be particularly interesting as the three EF seem to develop at different paces (for reviews, see Best \& Miller, 2010; Diamond, 2013; Karbach \& Unger, 2014). Specifically, previous literature shows that successfully inhibiting distracting stimuli and refraining from producing pre-dominant responses is a process that develops earlier in childhood, whereas flexibly shifting attentional resources between different task sets and successfully updating information in one's working memory develop at a later stage (Best et al., 2009; Hughes, 2011). Such developmental differences between the three EF may further contribute to (age-)differences in children's focal, nonfocal and time-based PM performance. In addition, the literature suggests that other cognitive domains are involved in successful PM, such as planning, goal management, intelligence, processing speed and metacognition (e.g., Cauvin, Moulin, Souchay, Schnitzspahn, \& Kliegel, 2018; Kliegel, McDaniel, \& Einstein, 2000; Scullin \& McDaniel, 2010). Future studies should administer an even broader variety of cognitive tests, allowing to compare the role of EF to the impact of other cognitive resources on PM development.

Finally, we have outlined how the differential association of EF and PM types was examined by previous studies and have argued that their inconclusive pattern of results was mainly due to a piecewise evaluation of EF and PM. An additional factor contributing to these mixed findings, however, may be that different studies choose different tasks to assess EF (again, see Best \& Miller, 2010 for an extensive overview). In this context, it is important to underline that most executive tasks are "task impure", meaning that deploy more than one EF at a time. For example, on a typical Go-NoGo task, participants have to refrain from answering to certain stimuli (thus mainly deploying inhibitory control), but they also have to hold in mind for which category of stimuli this rule applies (thus also requiring updating resources). Further, each of the three functions of the Miyake-model comprises multiple sub-processes (meaning that there are multiple rather than one type of inhibition, shifting and updating). For example, depending on the specific task choice, paradigms labeled as "inhibition tasks" can either evaluate participants" ability to inhibit a prepotent response (e.g., Go-NoGo tasks, Stop-signal tasks) or they can evaluate the ability to ignore distracting, non-pertinent information (e.g., Stroop tasks, Flanker tasks). Such discrepancies may further contribute to the inconclusive pattern presented by previous studies. With the aim of minimizing both issues as much as possible, we choose our executive tasks as a function of the processes that the literature associates to PM. For example, performing a prospective task requires participants to interrupt performing the ongoing task, (disengage from it) in order to perform the PM task. Thus, using an inhibition task that evaluates children's ability to interrupt an ongoing activity seems most appropriate to evaluate to role of inhibition in PM. Although our study therefore provides novel insights on the specific association of EF and different PM tasks, future studies will have to examine in further detail which sub-type of each EF specifically contributes to different types of PM.

In conclusion, the present study was the first to assess the three EF and the three PM tasks types in a single group of school-aged children in order to examine differential links between EF and PM in a multivariate approach. Findings clearly demonstrated ageincrements of executive capacities and of (nonfocal and time-based, but not focal) PM over childhood. Importantly, our findings show that age did not account for PM performance above and beyond executive resources, suggesting that increases in executive capacities account for PM improvements during school-age. In terms of PM task-specific EF contributions, our findings illustrate that 6- to 11year olds deploy updating for PM tasks in general, whereas inhibition and shifting may be more or less strongly recruited, depending on the qualities of the different PM tasks. Finally, the present study provides the first insight into the strategic (re-)allocation of cognitive resources, specifically during time-based PM tasks, which do not provide any external cues on when the PM task has to be performed and therefore crucially rely on self-initiated processes such as time-monitoring.

\section{Funding}

This work was supported by the Swiss National Science Foundation (SNSF) [GZ: 100014_152841/1].

\section{Acknowledgements}

The authors are grateful to Laura Abdili, Niloufar Anjileli, Chiara Bernasconi, Giuliano Bizon, Marie-France Bonny, Morgane Budry, Marie Bugnon, Solange Gautier, Maëlle Gousset, Ali Hedhili, Lea Maréchal, Elsa Martinelli, Cécile Mueller, Mélissa PegatToquet, Margaux Pimont, Félix Rambicur, Mélanie Silva Damil, Lysiane Sublet and Monika Toellner for their assistance in study preparation and data collection.

\section{References}


doi.org/10.1080/17405620802507707.

Aberle, I., Rendell, P. G., Rose, N. S., McDaniel, M. A., \& Kliegel, M. (2010). The age prospective memory paradox: Young adults may not give their best outside of the lab. Developmental Psychology, 46(6), 1444-1453. https://doi.org/10.1037/A0020718.

Altgassen, M., Kretschmer, A., \& Schnitzspahn, K. M. (2017). Future thinking instructions improve prospective memory performance in adolescents. Child Neuropsychology, 23(5), 536-553. https://doi.org/10.1080/09297049.2016.1158247.

Atance, C. M., \& Jackson, L. K. (2009). The development and coherence of future-oriented behaviors during the preschool years. Journal of Experimental Child Psychology, 102(4), 379-391. https://doi.org/10.1016/j.jecp.2009.01.001.

Atkinson, R. C., \& Shiffrin, R. M. (1968). Human memory: A proposed system and its control processes. In K. W. Spence, \& J. T. Spence (Vol. Eds.), The psychology of learning and motivation: 2, (pp. 89-195). New York: Academic Press.

Azzopardi, B., Auffray, C., \& Kermarrec, C. (2017). Paradoxical effect of aging on laboratory and naturalistic time-based prospective memory tasks. Role of executive functions. Canadian Journal on Aging/La Revue canadienne du vieillissement, 36(1), 30-40. https://doi.org/10.1017/S0714980816000738.

Berlin, L., \& Bohlin, G. (2002). Response inhibition, hyperactivity, and conduct problems among preschool children. Journal of Clinical Child and Adolescent Psychology, 31(2), 242-251. https://doi.org/10.1207/153744202753604511.

Best, J. R., \& Miller, P. H. (2010). A developmental perspective on executive function. Child Development, 81(6), 1641-1660. https://doi.org/10.1111/j.1467-8624. 2010.01499.x.

Best, J. R., Miller, P. H., \& Jones, L. L. (2009). Executive functions after age 5: Changes and correlates. Developmental Review, 29(3), 180-200. https://doi.org/10.1016/ j.dr.2009.05.002.

Brandimonte, M. A., Einstein, G. O., \& McDaniel, M. A. (1996). Prospective memory: Theory and application. Mahwah, NJ: Erlbaum.

Burgess, P. W., Alderman, N., Volle, E., Benoit, R. G., \& Gilbert, S. J. (2009). Mesulam's frontal lobe mystery re-examined. Restorative Neurology and Neuroscience, 27(5), 493-506. https://doi.org/10.3233/rnn-2009-0511.

Carlson, S. M., \& Moses, L. J. (2001). Individual differences in inhibitory control and children's theory of mind. Child Development, 72(4), 1032-1053. https://doi.org/ $10.1111 / 1467-8624.00333$

Causey, K. B., \& Bjorklund, D. F. (2014). Prospective memory in preschool children: Influences of agency, incentive, and underlying cognitive mechanisms. Journal of Experimental Child Psychology, 127, 36-51. https://doi.org/10.1016/j.jecp.2014.01.020.

Cauvin, S., Moulin, C., Souchay, C., Schnitzspahn, K., \& Kliegel, M. (2018). Laboratory vs. naturalistic prospective memory task predictions: Young adults are overconfident outside of the laboratory. Memory, 1-11. https://doi.org/10.1080/09658211.2018.1540703.

Ceci, S. J., \& Bronfenbrenner, U. (1985). Dont forget to take the cupcakes out of the oven - Prospective memory, strategic time-monitoring, and context. Child Development, 56(1), 152-164. https://doi.org/10.2307/1130182.

Chen, Y. Z., Lian, R., Yang, L. X., Liu, J. R., \& Meng, Y. F. (2017). Working memory load and reminder effect on event-based prospective memory of high- and lowachieving students in math. Journal of Learning Disabilities, 50(5), 602-608. https://doi.org/10.1177/0022219416668322.

Cottini, M., Basso, D., \& Palladino, P. (2018). The role of declarative and procedural metamemory in event-based prospective memory in school-aged children. Journal of Experimental Child Psychology, 166, 17-33. https://doi.org/10.1016/j.jecp.2017.08.002.

Crews, F., He, J., \& Hodge, C. (2007). Adolescent cortical development: A critical period of vulnerability for addiction. Pharmacology Biochemistry and Behavior, 86(2), 189-199. https://doi.org/10.1016/j.pbb.2006.12.001.

Davidson, M. C., Amso, D., Anderson, L. C., \& Diamond, A. (2006). Development of cognitive control and executive functions from 4 to 13 years: Evidence from manipulations of memory, inhibition, and task switching. Neuropsychologia, 44(11), 2037-2078. https://doi.org/10.1016/j.neuropsychologia.2006.02.006.

Diamond, A. (2013). Executive functions. Annual Review of Psychology, 64, 135-168. https://doi.org/10.1146/annurev-psych-113011-143750.

Duncan, J. (1984). Selective attention and the organization of visual information. Journal of Experimental Psychology-General, 113(4), 501-517. https://doi.org/10. 1037/0096-3445.113.4.501.

Einstein, G. O., Richardson, S. L., Guynn, M. J., Cunfer, A. R., \& McDaniel, M. A. (1995). Aging and prospective memory - examining the influences of self-initiated retrieval-processes. Journal of Experimental Psychology-Learning Memory and Cognition, 21(4), 996-1007. https://doi.org/10.1037/0278-7393.21.4.996.

Ellis, J., \& Kvavilashvili, L. (2000). Prospective memory in 2000: Past, present, and future directions. Applied Cognitive Psychology, 14, S1-S9. https://doi.org/10.1002/ Acp.767.Abs.

Engle, R. W. (2002). Working memory capacity as executive attention. Current Directions in Psychological Science, 11(1), 19-23. https://doi.org/10.1111/1467-8721. 00160.

Ford, R. M., Driscoll, T., Shum, D., \& Macaulay, C. E. (2012). Executive and theory-of-mind contributions to event-based prospective memory in children: Exploring the self-projection hypothesis. Journal of Experimental Child Psychology, 111(3), 468-489. https://doi.org/10.1016/j., jecp.2011.10.006.

Friedman, N. P., \& Miyake, A. (2017). Unity and diversity of executive functions: Individual differences as a window on cognitive structure. Cortex, 86(Suppl. C), 186-204. https://doi.org/10.1016/j.cortex.2016.04.023.

Gade, M., Schuch, S., Druey, M. D., \& Koch, I. (2014). Inhibitory control in task switching. New York, NY: Oxford University Press.

Geurten, M., Lejeune, C., \& Meulemans, T. (2016). Time's up! Involvement of metamemory knowledge, executive functions, and time monitoring in children's prospective memory performance. Child Neuropsychology, 22(4), 443-457. https://doi.org/10.1080/09297049.2014.998642.

Gonneaud, J., Kalpouzos, G., Bon, L., Viader, F., Eustache, F., \& Desgranges, B. (2011). Distinct and shared cognitive functions mediate event- and time-based prospective memory impairment in normal ageing. Memory, 19(4), 360-377. https://doi.org/10.1080/09658211.2011.570765.

Guajardo, N. R., \& Best, D. L. (2000). Do preschoolers remember what to do?. Incentive and external cues in prospective memory. Cognitive Development, 15(1), 75-97. https://doi.org/10.1016/S0885-2014(00)00016-2.

Hughes, C. (2011). Changes and challenges in 20 years of research into the development of executive functions. Infant and Child Development, 20(3), 251-271. https:// doi.org/10.1002/icd.736.

Huizinga, M., Dolan, C. V., \& van der Molen, M. W. (2006). Age-related change in executive function: Developmental trends and a latent variable analysis. Neuropsychologia, 44(11), 2017-2036. https://doi.org/10.1016/j.neuropsychologia.2006.01.010.

Jaeggi, S. M., Buschkuehl, M., Jonides, J., \& Shah, P. (2011). Short- and long-term benefits of cognitive training. Proceedings of the National Academy of Sciences of the United States of America, 108(25), 10081-10086. https://doi.org/10.1073/pnas.1103228108.

Jaeggi, S. M., Studer-Luethi, B., Buschkuehl, M., Su, Y. F., Jonides, J., \& Perrig, W. J. (2010). The relationship between n-back performance and matrix reasoning implications for training and transfer. Intelligence, 38(6), 625-635. https://doi.org/10.1016/j.intell.2010.09.001.

Karbach, J., \& Unger, K. (2014). Executive control training from middle childhood to adolescence. Frontiers in Psychology, 5(390), https://doi.org/10.3389/fpsyg.2014. 00390.

Kerns, K. A. (2000). The CyberCruiser: An investigation of development of prospective memory in children. Journal of the International Neuropsychological Society, 6(1), $62-70$.

Klaver, P., Marcar, V., \& Martin, E. (2011). Neurodevelopment of the visual system in typically developing children. In O. Braddick, J. Atkinson, \& G. M. Innocenti (Vol. Eds.), Gene Expression to Neurobiology and Behavior: Human Brain Development and Developmental Disorders: 189, (pp. 113-136). Amsterdam: Elsevier Science Bv.

Kliegel, M., \& Jäger, T. (2007). The effects of age and cue-action reminders on event-based prospective memory performance in preschoolers. Cognitive Development, 22(1), 33-46. https://doi.org/10.1016/J. Cogdev.2006.08.003.

Kliegel, M., Mackinlay, R., \& Jäger, T. (2008). A life-span approach to the development of complex prospective memory. In M. Kliegel, M. A. McDaniel, \& G. O. Einstein (Eds.). Prospective memory: Cognitive, neuroscience, developmental, and applied perspectives (pp. 187-216). Mahwah, NJ: Lawrence Erlbaum Associates.

Kliegel, M., Mahy, C. E. V., Voigt, B., Henry, J. D., Rendell, P. G., \& Aberle, I. (2013). The development of prospective memory in young schoolchildren: The impact of ongoing task absorption, cue salience, and cue centrality. Journal of Experimental Child Psychology, 116(4), 792-810. https://doi.org/10.1016/j., jecp.2013.07.012.

Kliegel, M., \& Martin, M. (2003). Prospective memory research: Why is it relevant? International Journal of Psychology, 38(4), 193-194. https://doi.org/10.1080/ 00207590244000205. 
Kliegel, M., Martin, M., McDaniel, M. A., \& Einstein, G. O. (2002). Complex prospective memory and executive control of working memory: A process model. Psychologische Beiträge, 22, 303-318.

Kliegel, M., McDaniel, M. A., \& Einstein, G. O. (2000). Plan formation, retention, and execution in prospective memory: A new approach and age-related effects. Memory \& Cognition, 28(6), 1041-1049. https://doi.org/10.3758/Bf03209352.

Koch, I., Gade, M., Schuch, S., \& Philipp, A. M. (2010). The role of inhibition in task switching: A review. Psychonomic Bulletin \& Review, 17(1), 1-14. https://doi.org/ 10.3758/pbr.17.1.1.

Kretschmer, A., Voigt, B., Friedrich, S., Pfeiffer, K., \& Kliegel, M. (2014). Time-based prospective memory in young children-Exploring executive functions as a developmental mechanism. Child Neuropsychology, 20(6), 662-676. https://doi.org/10.1080/09297049.2013.841881.

Kvavilashvili, L., \& Ellis, J. (1996). Varieties of intention: Some distinctions and classifications. In M. Brandimonte, G. O. Einstein, \& M. A. McDaniel (Eds.). Prospective memory: Theory and applications. Mahwah: Erlbaum.

Kvavilashvili, L., Messer, D. J., \& Ebdon, P. (2001). Prospective memory in children: The effects of age and task interruption. Developmental Psychology, 37(3), 418-430. https://doi.org/10.1037/0012-1649.37.3.418.

Lange-Küttner, C. (2000). The role of object violation in the development of visual analysis. Perceptual and Motor Skills, 90(1), 3-24. https://doi.org/10.2466/Pms.90. 1.3-24.

Mackinlay, R. J., Kliegel, M., \& Mantyla, T. (2009). Predictors of time-based prospective memory in children. Journal of Experimental Child Psychology, 102(3), 251-264. https://doi.org/10.1016/J. Jecp.2008.08.006.

Mahy, C. E. V., Mazachowsky, T. R., \& Pagobo, J. R. (2018). Do verbal reminders improve preschoolers' prospective memory performance? It depends on age and individual differences. Cognitive Development, 47, 158-167. https://doi.org/10.1016/j.cogdev.2018.06.004.

Mahy, C. E. V., Mohun, H., Muller, U., \& Moses, L. J. (2016). The role of subvocal rehearsal in preschool children's prospective memory. Cognitive Development, 39, 189-196. https://doi.org/10.1016/j.cogdev.2016.07.001.

Mahy, C. E. V., \& Moses, L. J. (2011). Executive functioning and prospective memory in young children. Cognitive Development, 26(3), 269-281. https://doi.org/10. 1016/j.cogdev.2011.06.002.

Mahy, C. E. V., Moses, L. J., \& Kliegel, M. (2014a). The development of prospective memory in children: An executive framework. Developmental Review, 34(4), 305-326. https://doi.org/10.1016/j.dr.2014.08.001.

Mahy, C. E. V., Moses, L. J., \& Kliegel, M. (2014b). The impact of age, ongoing task difficulty, and cue salience on preschoolers' prospective memory performance: The role of executive function. Journal of Experimental Child Psychology, 127, 52-64. https://doi.org/10.1016/j.jecp.2014.01.006.

Mahy, C. E. V., \& Munakata, Y. (2015). Transitions in executive function: Insights from developmental parallels between prospective memory and cognitive flexibility. Child Development Perspectives, 9(2), 128-132. https://doi.org/10.1111/cdep.12121.

Mantyla, T., Carelli, M. G., \& Forman, H. (2007). Time monitoring and executive functioning in children and adults. Journal of Experimental Child Psychology, 96(1), 1-19. https://doi.org/10.1016/j.jecp.2006.08.003.

Maylor, E. A., \& Logie, R. H. (2010). A large-scale comparison of prospective and retrospective memory development from childhood to middle age. Quarterly Journal of Experimental Psychology, 63(3), 442-451. https://doi.org/10.1080/17470210903469872.

McCauley, S. R., \& Levin, H. S. (2004). Prospective memory in pediatric traumatic brain injury: A preliminary study. Developmental Neuropsychology, 25(1-2), 5-20. https://doi.org/10.1080/87565641.2004.9651919.

McDaniel, M. A., \& Einstein, G. O. (2000). Strategic and automatic processes in prospective memory retrieval: A multiprocess framework. Applied Cognitive Psychology, 14, 127-144. https://doi.org/10.1002/acp.775.

Miyake, A., Friedman, N. P., Emerson, M. J., Witzki, A. H., Howerter, A., \& Wager, T. D. (2000). The unity and diversity of executive functions and their contributions to complex "frontal lobe" tasks: A latent variable analysis. Cognitive Psychology, 41(1), 49-100. https://doi.org/10.1006/cogp.1999.0734.

Nigro, G., Senese, V. P., Natullo, O., \& Sergi, I. (2002). Preliminary remarks on type of task and delay in children's prospective memory. Perceptual and Motor Skills, 95(2), 515-519. https://doi.org/10.2466/Pms.95.5.515-519.

Norman, D. A., \& Shallice, T. (1986). Attention to action: Willed and automatic control of behaviour. In R. J. Davidson, G. E. Schwartz, \& D. Shapiro (Vol. Eds.), Consciousness and Self-Regulation: Advances in Research and Theory: 4, (pp. 1-18). New York: Plenum Press.

Okuda, J., Fujii, T., Yamadori, A., Kawashima, R., Tsukiura, T., Fukatsu, R., et al. (1998). Participation of the prefrontal cortices in prospective memory: Evidence from a PET study in humans. Neuroscience Letters, 253(2), 127-130. https://doi.org/10.1016/S0304-3940(98)00628-4.

Parrish, E. E., Giaschi, D. E., Boden, C., \& Dougherty, R. (2005). The maturation of form and motion perception in school age children. Vision Research, 45(7), 827-837. https://doi.org/10.1016/j.visres.2004.10.005.

Passolunghi, M. C., \& Pazzaglia, F. (2005). A comparison of updating processes in children good or poor in arithmetic word problem-solving. Learning and Individual Differences, 15(4), 257-269. https://doi.org/10.1016/j.lindif.2005.03.001.

Remington, A., Cartwright-Finch, U., \& Lavie, N. (2014). I can see clearly now: The effects of age and perceptual load on inattentional blindness. Frontiers in Human Neuroscience, 8(229), https://doi.org/10.3389/fnhum.2014.00229.

Rendell, P. G., Vella, M. J., Kliegel, M., \& Terrett, G. (2009). Effect of delay on children's delay-execute prospective memory performance. Cognitive Development, 24(2), 156-168. https://doi.org/10.1016/j.cogdev.2008.12.002.

Robey, A., Buckingham-Howes, S., Salmeron, B. J., Black, M. M., \& Riggins, T. (2014). Relations among prospective memory, cognitive abilities, and brain structure in adolescents who vary in prenatal drug exposure. Journal of Experimental Child Psychology, 127(Supplement C), 144-162. https://doi.org/10.1016/j.jecp.2014.01. 008 .

Schnitzspahn, K. M., Stahl, C., Zeintl, M., Kaller, C. P., \& Kliegel, M. (2013). The role of shifting, updating, and inhibition in prospective memory performance in young and older adults. Developmental Psychology, 49(8), 1544-1553. https://doi.org/10.1037/a0030579.

Schulz, K. P., Fan, J., Magidina, O., Marks, D. J., Hahn, B., \& Halperin, J. M. (2007). Does the emotional go/no-go task really measure behavioral inhibition? Convergence with measures on a non-emotional analog. Archives of Clinical Neuropsychology, 22(2), 151-160. https://doi.org/10.1016/j.acn.2006.12.001.

Scullin, M. K., \& McDaniel, M. A. (2010). Remembering to execute a goal: Sleep on it!. Psychological Science, 21(7), 1028-1035. https://doi.org/10.1177/ 0956797610373373.

Scullin, M. K., McDaniel, M. A., Shelton, J. T., \& Lee, J. H. (2010). Focal/nonfocal cue effects in prospective memory: Monitoring difficulty or different retrieval processes? Journal of Experimental Psychology-Learning Memory and Cognition, 36(3), 736-749. https://doi.org/10.1037/A0018971.

Shallice, T., \& Burgess, P. (1996). Executive and cognitive functions of the prefrontal cortex - The domain of supervisory processes and temporal organization of behaviour. Philosophical Transactions of the Royal Society of London. Series B: Biological Sciences, 351(1346), 1405-1412. https://doi.org/10.1098/rstb.1996.0124.

Shallice, T., \& Burgess, P. W. (1991). Deficits in strategy application following frontal-lobe damage in man. Brain, 114, 727-741. https://doi.org/10.1093/brain/114. 2.727.

Shum, D., Cross, B., Ford, R., \& Ownsworth, T. (2008). A developmental investigation of prospective memory: Effects of interruption. Child Neuropsychology, 14(6), 547-561. https://doi.org/10.1080/09297040801947051.

Smith, R. E., Bayen, U. J., \& Martin, C. (2010). The cognitive processes underlying event-based prospective memory in school-age children and young adults: A formal model-based study. Developmental Psychology, 46(1), 230-244. https://doi.org/10.1037/A0017100.

Somerville, S. C., Wellman, H. M., \& Cultice, J. C. (1983). Young childrens deliberate reminding. Journal of Genetic Psychology, 143(1), 87-96.

Sowell, E. R., Delis, D., Stiles, J., \& Jernigan, T. L. (2001). Improved memory functioning and frontal lobe maturation between childhood and adolescence: A structural MRI study. Journal of the International Neuropsychological Society, 7(3), 312-322.

Spiess, M. A., Meier, B., \& Roebers, C. M. (2015). Prospective memory, executive functions, and metacognition are already differentiated in young elementary school children evidence from latent Factor Modeling. Swiss Journal of Psychology, 74(4), 229-241. https://doi.org/10.1024/1421-0185/a000165.

Spiess, M. A., Meier, B., \& Roebers, C. M. (2016). Development and longitudinal relationships between children's executive functions, prospective memory, and metacognition. Cognitive Development, 38, 99-113. https://doi.org/10.1016/j.cogdev.2016.02.003.

Stuss, D. T., \& Alexander, M. P. (2000). Executive functions and the frontal lobes: A conceptual view. Psychological Research, 63(3), 289-298. https://doi.org/10.1007/ 
s004269900007.

Thorell, L. B., Lindqvist, S., Nutley, S. B., Bohlin, G., \& Klingberg, T. (2009). Training and transfer effects of executive functions in preschool children. Developmental Science, 12(1), 106-113. https://doi.org/10.1111/j.1467-7687.2008.00745.x.

Ungerleider, L. G., \& Mishkin, M. (1982). Two cortical visual systems. In D. J. Ingle, M. A. Goodale, \& R. J. W. Mansfield (Eds.). Analysis of visual behavior (pp. 549586). Cambridge: MIT Press.

Voigt, B., Aberle, I., Schonfeld, J., \& Kliegel, M. (2011). Time-based prospective memory in schoolchildren the role of self-initiation and strategic time monitoring. Zeitschrift Fur Psychologie-Journal of Psychology, 219(2), 92-99. https://doi.org/10.1027/2151-2604/A000053.

Voigt, B., Mahy, C. E. V., Ellis, J., Schnitzspahn, K., Krause, I., Altgassen, M., et al. (2014). The development of time-based prospective memory in childhood: The role of working memory updating. Developmental Psychology, 50(10), 2393-2404. https://doi.org/10.1037/a0037491.

Wang, L., Altgassen, M., Liu, W., Xiong, W. R., Akgun, C., \& Kliegel, M. (2011). Prospective memory across adolescence: The effects of age and cue focality. Developmental Psychology, 47(1), 226-232. https://doi.org/10.1037/a0021306.

Wang, L., Kliegel, M., Liu, W., \& Yang, Z. L. (2008). Prospective memory performance in preschoolers: Inhibitory control matters. European Journal of Developmental Psychology, 5(3), 289-302. https://doi.org/10.1080/17405620600778161.

Wang, L., Kliegel, M., Yang, Z. L., \& Liu, W. (2006). Prospective memory performance across adolescence. Journal of Genetic Psychology, 167(2), 179-188. https://doi. org/10.3200/Gntp.167.2.179-188.

Wechsler, D. (2004). The Wechsler intelligence scale for children-Fourth edition. San Antonio, TX: Pearson Assessment.

West, R., \& Craik, F. I. M. (2001). Influences on the efficiency of prospective memory in younger and older adults. Psychology and Aging, 16(4), 682-696. https://doi. org/10.1037//0882-7974.16.4.682.

Williams, D., Boucher, J., Lind, S., \& Jarrold, C. (2013). Time-based and event-based prospective memory in autism spectrum disorder: The roles of executive function and theory of mind, and time-estimation. Journal of Autism and Developmental Disorders, 43(7), 1555-1567. https://doi.org/10.1007/s10803-012-1703-9.

Yang, T. X., Chan, R. C. K., \& Shum, D. (2011). The development of prospective memory in typically developing children. Neuropsychology, 25(3), 342-352. https:// doi.org/10.1037/A0022239.

Yi, L., Fan, Y., Joseph, L., Huang, D., Wang, X., Li, J., et al. (2014). Event-based prospective memory in children with autism spectrum disorder: The role of executive function. Research in Autism Spectrum Disorders, 8(6), 654-660. https://doi.org/10.1016/j.rasd.2014.03.005.

Zamroziewicz, M., Raskin, S. A., Tennen, H., Austad, C. S., Wood, R. M., Fallahi, C. R., et al. (2017). Effects of drinking patterns on prospective memory performance in college students. Neuropsychology, 31(2), 191-199. https://doi.org/10.1037/neu0000313.

Zelazo, P. D., Carlson, S. M., \& Kesek, A. (2008). Development of executive function in childhood. In C. A. Nelson, \& M. Luciana (Vol. Eds.), Handbook of developmental cognitive neuroscience: vol. 2, (pp. 553-574). Cambridge, MA: MIT Press.

Zhang, X., Zuber, S., Liu, S., Kliegel, M., \& Wang, L. (2017). The effects of task instructor status on prospective memory performance in preschoolers. European Journal of Developmental Psychology, 14(1), 102-177. https://doi.org/10.1080/17405629.2016.1165660.

Zimmermann, T. D., \& Meier, B. (2006). The rise and decline of prospective memory performance across the lifespan. Quarterly Journal of Experimental Psychology, 59(12), 2040-2046. https://doi.org/10.1080/17470210600917835.

Zöllig, J., West, R., Martin, M., Altgassen, M., Lemke, U., \& Kliegel, M. (2007). Neural correlates of prospective memory across the lifespan. Neuropsychologia, 45(14), 3299-3314. https://doi.org/10.1016/J.Neuropsychologia.2007.06.010.

Zuber, S., Kliegel, M., \& Ihle, A. (2016). An individual difference perspective on focal versus nonfocal prospective memory. Memory \& Cognition, 44(8), 1192-1203. https://doi.org/10.3758/s13421-016-0628-5. 